\title{
BMJ Open Pharmacists' response to anaphylaxis in the community (PRAC): a randomised, simulated patient study of pharmacist practice
}

\author{
Sandra M Salter, ${ }^{1}$ Brock Delfante, ${ }^{1}$ Sarah de Klerk, ${ }^{1}$ Frank M Sanfilippo, ${ }^{2}$ \\ Rhonda M Clifford ${ }^{1}$
}

To cite: Salter SM,

Delfante B, de Klerk S, et al. Pharmacists' response to anaphylaxis in the community (PRAC): a randomised, simulated patient study of pharmacist practice. BMJ Open 2014;4: e005648. doi:10.1136/ bmjopen-2014-005648

- Prepublication history and additional material is available. To view please visit the journal (http://dx.doi.org/ 10.1136/bmjopen-2014005648).

Received 7 May 2014 Revised 19 June 2014 Accepted 20 June 2014

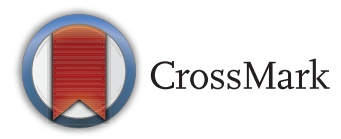

${ }^{1}$ Pharmacy Program, Centre for Optimization of Medicines, School of Medicine and Pharmacology, The University of Western Australia, Crawley, Western Australia, Australia

${ }^{2}$ School of Population Health, The University of Western Australia, Crawley, Western Australia, Australia

Correspondence to

Sandra M Salter;

sandra.salter@uwa.edu.au

\section{ABSTRACT}

Objective: To evaluate how community pharmacists manage patients with anaphylaxis.

Design: A randomised, cross-sectional, simulated patient study of community pharmacist practice.

Setting: 300 metropolitan pharmacies located in Perth Australia, randomised to three groups of 100 pharmacies. Each group corresponded to a different epinephrine autoinjector: original EpiPen, new-look EpiPen or Anapen.

Participants: 300 pharmacies were visited with 271 simulated patient visits included in the final analysis (88=original EpiPen, 92=new-look EpiPen, 91=Anapen).

Outcome measures: Primary anaphylaxis preparedness (readiness to treat acute anaphylaxis). Secondary anaphylaxis engagement (willingness to engage the patient in a discussion about their anaphylaxis).

Methods: Simulated patients approached pharmacists, using a standardised scenario, for assistance with epinephrine autoinjector use and advice about the use of antihistamines in anaphylaxis. Scores for each outcome were obtained based on the number of predefined statements addressed by the pharmacist during the consultation (maximum score $=5$ for preparedness and 8 for engagement).

Results: The mean anaphylaxis preparedness score was 2.39 points (SD 1.17). Scores for new-look EpiPen were significantly higher than for original EpiPen and Anapen (2.75 vs 2.38 points, $p=0.027$; 2.75 vs 2.03 points, $p<0.001$, respectively). Overall, $17.3 \%$ of pharmacists correctly demonstrated the epinephrine autoinjector. The mean anaphylaxis engagement score was 3.11 points (SD 1.73). Scores for new-look EpiPen were similar to original EpiPen and Anapen (3.11 vs 3.32 points; 3.11 vs 2.90 points, both $p=0.42$ ). Engagement was associated with preparedness. For each additional engagement point, preparedness increased by $7 \%(0.357$ points; $95 \% \mathrm{Cl}$ 0.291 to $0.424 ; p<0.001$ ).

Conclusions: Pharmacists demonstrated reasonable knowledge of anaphylaxis symptoms and emergency care, but had poor epinephrine autoinjector technique and rarely discussed anaphylaxis action plans. Pharmacists who had a more comprehensive
Strengths and limitations of this study

- This is the first study to consider pharmacists management of anaphylaxis, in terms of readiness to treat acute anaphylaxis, and the impact of various factors on such readiness (including willingness to comprehensively discuss anaphylaxis with patients).

- Simulated patient methodology, with rigorous tool development, training, evaluation and pilot testing prior to the study was successfully employed to measure true pharmacist practice. There was a risk of recall bias in data collection (which could underestimate real behaviour by $10-20 \%$ ), however this was minimised by capping the number of simulated patient visits per day, and requiring immediate data collation after each visit.

- Outcome measures were defined based on national and international pharmacy practice and anaphylaxis guidelines, however we did not assess whether the pharmacist advised the patient to lay flat. Although this may have distorted true anaphylaxis preparedness, we did not assess this point because of the dissimilarity between the scenario and a real anaphylaxis emergency.

discussion about anaphylaxis with patients, were more prepared for anaphylaxis emergencies. Future research should evaluate the nature and significance of errors in pharmacists' autoinjector technique.

\section{INTRODUCTION}

Anaphylaxis is a severe, progressive allergic reaction that is rapid in onset and might cause death. ${ }^{1}$ The lifetime prevalence of anaphylaxis in developed countries has been estimated at $1-2 \% .^{2-4}$ However, it is difficult to accurately quantify anaphylaxis: diagnosis is based on clinical judgement and may at times be missed; coding in hospitals and prehospital emergency services is inconsistent; 
and no standard mechanism exists for reporting new cases of anaphylaxis. Further, patients may misinterpret symptoms of anaphylaxis and up to 50\% may not seek emergency treatment during or after initial events. ${ }^{1}{ }^{5-11}$

Nonetheless anaphylaxis rates in Australia are increasing, in line with worldwide trends. ${ }^{7}{ }^{12-15}$ Between 1993-1994 and 2004-2005 anaphylaxis hospitalisations in Australia increased from 3.7 to $10.8 / 100000$ population; an average annual increase of $8.8 \% .{ }^{13}$ Much of this increase is attributed to food-induced anaphylaxis-the most common cause of anaphylaxis in the community setting (and responsible for $30 \%$ of all fatal anaphylaxis cases). ${ }^{2} 813$ Notably, Australia has the highest rate of food allergy in the world, with challenge-proven prevalence of more than $10 \%$ in young children. ${ }^{16} 17$

Treatment of anaphylaxis requires prompt administration of epinephrine. Delayed epinephrine is associated with more severe reactions and fatal anaphylaxis. ${ }^{1} 10$ 18-20 Epinephrine autoinjector devices are often prescribed for patients with a history of anaphylaxis to allow early self-management of recurrent events, yet the majority of patients do not understand how or when to use them. ${ }^{6} 91119$ A survey of 1885 patients who had experienced anaphylaxis found $73 \%$ did not use epinephrine, and in this group $28 \%$ had not previously received a prescription for epinephrine. ${ }^{9}$

Therefore, considering (1) the complexities of diagnosis and variations in signs and symptoms of anaphylaxis; (2) the uncertain yet increasing burden of disease; (3) the need for urgent epinephrine during anaphylaxis and (4) the likelihood for people to be unprepared for anaphylaxis in the community, the options for management of acute anaphylaxis in this setting warrant consideration. Patients may attend hospitals, call emergency services, try a medical practitioner or self-manage. However, there is increasing anecdotal evidence that some patients choose to attend their local pharmacy instead. This may be because patients or carers do not recognise the symptoms, or understand the treatment of anaphylaxis and instead seek (erroneously) to purchase antihistamines from their pharmacist. Those who do identify the need for immediate treatment may choose the pharmacist for reasons of urgent accessibility, familiarity, convenience and awareness that pharmacies stock epinephrine autoinjectors.

While there is good evidence for the roles of the patient, medical practitioner, emergency services and hospital personnel in the management of anaphylaxis, ${ }^{20-22}$ evidence for the role of the community pharmacist is scarce. Surveys of opinions about treating anaphylaxis, and epinephrine autoinjector technique exist, ${ }^{23-27}$ but there is no research evaluating pharmacist practice or preparedness for anaphylaxis emergencies. We believe that patients will increasingly seek out pharmacists for anaphylaxis first aid. Given the unpredictable nature of anaphylaxis, the dramatic rise in food-induced anaphylaxis, the potential for first-time reactions to be fatal, ${ }^{28}$ and the accessibility of pharmacists as a treatment destination, there is an urgent need to identify if pharmacists are ready to manage anaphylaxis. An important duality in anaphylaxis management must be considered - first providing first aid when required, and second engaging the non-acute patient in discussion so they may be prepared for future events. The purpose of this study of Australian community pharmacist practice was to identify (1) their preparedness for acute anaphylaxis; (2) factors that impact on such preparedness and (3) willingness to engage the patient in a discussion about anaphylaxis.

\section{METHODS}

We conducted a randomised, cross-sectional, simulated patient study of pharmacist practice in Perth, Australia from April to May 2012.

\section{Setting and recruitment}

All Perth metropolitan pharmacies located within a $20 \mathrm{~km}$ radius of the Perth Central Business District, and listed on the Pharmacy Registration Board of Western Australia Premises Register ${ }^{29}$ were included in the sampling frame $(\mathrm{n}=334)$. A random sample of 300 pharmacies was selected using a random numbers generator, ${ }^{30}$ and then further randomised into three groups of 100 pharmacies. Each pharmacy was visited once by one of three researchers, who enacted a standardised simulated patient scenario, designed to build a profile of a patient who had recently experienced anaphylaxis for the first time.

\section{Exclusions}

Hospital dispensaries and compounding pharmacies were excluded as they may not routinely supply epinephrine autoinjectors or be directly accessible by patients. Where the researcher recognised the pharmacist or any other staff member on duty, the visit was abandoned and the pharmacy excluded.

\section{Anaphylaxis management}

We considered preparedness for acute anaphylaxis as the primary outcome and willingness to engage the patient in a discussion about their anaphylaxis as a secondary outcome (box 1). As there are no guidelines specific to pharmacist care for patients with anaphylaxis in Australia, we used key statements from the Australasian Society of Clinical Immunology and Allergy (ASCIA) Action Plan for Anaphylaxis $^{31}$ and the World Allergy Organization (WAO) Anaphylaxis Guidelines, ${ }^{20}$ to define the primary outcome. We added concepts from Australian Professional Practice Standards, ${ }^{32}$ and National Competency Standards Framework for Pharmacists in Australia ${ }^{33}$ to define the secondary outcome.

\section{Scenario}

At each pharmacy, the patient asked to speak with the pharmacist, requested explanation of their epinephrine autoinjector device, and asked about the use of 


\section{Box 1 Anaphylaxis management}

Anaphylaxis preparedness (readiness to treat acute anaphylaxis)

1. Identify the symptoms of anaphylaxis

2. Identify the need for hospital care after administering an epinephrine autoinjector

3. Identify the need for an action plan for anaphylaxis

4. Correctly demonstrate an epinephrine autoinjector device*

5. Demonstrate an understanding that antihistamines are ineffective in treating acute anaphylaxist

Anaphylaxis engagement (willingness to engage the patient in a discussion about their anaphylaxis)

1. Ask specifically about the allergen that caused anaphylaxis

2. Confirm specialist medical follow-up planned

3. Physically demonstrate the epinephrine autoinjectorł

4. Provide written material on how to use the epinephrine autoinjector

5. Provide advice about autoinjector storage

6. Check epinephrine autoinjector expiry date

7. Explain the side effects of epinephrine

8. General anaphylaxis advice provided without prompt§

${ }^{*}$ Required all device administration steps on the relevant ASCIA Action Plan for Anaphylaxis to be either performed or explained. †Pharmacist stated one or more of: antihistamines ineffective in treating anaphylaxis; anaphylaxis occurs too fast for an antihistamine to be of benefit; if no improvement after antihistamine, administer epinephrine autoinjector.

‡Pharmacist used either the patient's 'live' autoinjector or a trainer device to perform hands-on demonstration.

§Patient requested information on the use of antihistamines in anaphylaxis after the device demonstration was complete. Where the pharmacist had not provided anaphylaxis advice and was preparing to conclude the consultation before this request, then the request was considered to be a prompt for further anaphylaxis advice.

antihistamines in anaphylaxis. Additional scenario information was provided only when the patient responded to direct pharmacist questions (box 2). At the time of this research, availability of epinephrine autoinjector devices in Australia was changing. Original EpiPen was being replaced by new-look EpiPen and Anapen had been available as an alternative device for less than 2 years. Thus we considered it important to identify if older or newer devices corresponded with better management, and each researcher applied one of these devices in their scenario request. Devices were allocated to researchers randomly. Original EpiPen was allocated to a female Master of Pharmacy student, aged 2025 years. New-look EpiPen was allocated to a male Master of Pharmacy student, aged 20-25 years. Anapen was allocated to an experienced simulated patient actor (female, aged $40-45$ years).

We conducted a full-day training session where simulated patients performed the scenario and, to ensure familiarity, practised device demonstration. Pharmacist questions were anticipated and practised; modifications to patient answers were made to ensure the scenario was memorable for the actor and realistic for the pharmacist. Finally, devices used during the study were

\section{Box 2 Scenario description}

\section{Scenario}

The patient was taken by ambulance to hospital 'a week ago' with their first episode of anaphylaxis.

They now have two epinephrine autoinjector devices (of the same type) but do not know how or when to use them.

The patient is uncertain about what they should do if they have another episode of anaphylaxis.

"Hi, could I please speak to the pharmacist?

[Pharmacist attends]. I have recently been given this, [show adrenaline autoinjector], but I don't know how to use it. Could you show me?"

During the ensuing discussion, the patient asked:

"I've also been told I can use antihistamines. What do you think?" Responses were provided (as follows) to questions asked by the pharmacist. No additional information was volunteered. The patient accepted all advice provided by the pharmacist without question.

Anaphylaxis background

Where did you get that? My relative picked it up for me when I came home from the hospital.

When did you go to hospital? Last week.

Did you have anaphylaxis last week when you went to hospital? Yes that's what the doctor said.

What happened? I was having dinner, eating prawns at a friend's house when I started coughing and found it hard to breathe. I got a rash on my face and chest, and the breathing got more and more difficult, so my friends called an ambulance. I spent the night in $E D$.

\section{Antihistamine request}

Who told you that? Someone at the hospital.

What were you told to use an antihistamine for? I can't remember but I suppose it's for my allergy.

Have you taken an antihistamine before? No.

Do you prefer a sedating or non-sedating antihistamine? Whatever you recommend.

Any allergies? I think I am allergic to prawns.

Medical conditions? Mild eczema on and off.

Have you used anything before for allergy? No.

Are you seeing an allergy specialist? Yes, in two weeks' time.

Do you have an Action Plan for Anaphylaxis? No.

If an antihistamine was offered for sale, the patient agreed and made the purchase.

replenished as required to ensure they looked 'new' for each pharmacy visit.

\section{Data collection}

We developed a data collection tool specifically for this study. To aid recall, variables were ordered in sections to present a logical flow for recording that matched the anticipated flow of the scenario. Preparedness variables (broadly: allergy assessment, autoinjector demonstration, antihistamine recommendations) and demographic variables (broadly: pharmacy environment, pharmacist age and gender) were collected (see online supplementary appendix 1). Prior to use, the tool was evaluated for face validity in a group of 10 pharmacists and evaluated for usability in a round-table discussion during the 
training session. To reduce the potential for scenario and data collection fatigue, researchers were limited to a maximum of eight pharmacy visits per day, 5 days per week. The tool was completed immediately after each pharmacy visit (away from the premises), and data subsequently entered to a database (Microsoft Excel, Microsoft Corporation, Redmond, USA). During the study, an independent auditor crosschecked a random sample of 30 completed tools against data entered in the database. The proportion of records in disagreement was $0.27 \%$.

\section{Scenario pilot}

The final scenario and data collection tool were piloted in a random sample of nine pharmacies ( 3 per device). The scenario remained unchanged. Minor additions to the tool were made prior to the main study. Pharmacies visited in the pilot were not included in the final analysis.

\section{Analysis}

All analyses were performed using SPSS V.21 (IBM, New York, USA), and reported as two-sided $p$ values with a 5\% level of significance. Descriptive statistics were obtained for demographic and preparedness variables by autoinjector group, and assessed using Pearson $\chi^{2}$ test or Fisher's exact test.

Scores for each outcome were obtained based on the number of statements addressed during the consultation (box 1), with 'anaphylaxis preparedness' being the score for the primary outcome (maximum=5), and 'anaphylaxis engagement' as the score for the secondary outcome $($ maximum $=8)$. One-way analysis of variance with post hoc pairwise analysis was used to evaluate differences in mean preparedness scores by autoinjector group.

Multiple linear regression was performed to identify factors impacting on anaphylaxis preparedness. We specified anaphylaxis preparedness score as the dependent variable. Pharmacy type and location; pharmacist gender, estimated age and how busy they were (as a ratio of total customers in store to total pharmacy staff); time of day the visit was performed; type of autoinjector demonstrated; and anaphylaxis engagement score were covariates. We used a backward automated model selection approach to identify significant factors impacting on anaphylaxis preparedness. We did not include antihistamine sales data in the model because fewer than half of all consultations resulted in a sale. Instead, advice provided with the sale of an antihistamine was analysed descriptively by epinephrine autoinjector group.

As there were no reliable estimates for expected SD in anaphylaxis preparedness score, we did not conduct a priori sample size calculations. However, a post hoc power calculation using the sample sizes of $n=92$ (new-look EpiPen) and n=91 (Anapen), with an observed SD of 1.17 points, showed our study had at least $82 \%$ power to detect a difference in anaphylaxis preparedness score of 0.5 points or more between groups at the $5 \%$ level of significance. ${ }^{34}$

\section{RESULTS}

We visited all 300 pharmacies randomised to the study, and included $271(90 \%)$ of the visits in the final analysis (figure 1). Descriptive results are reported in table 1 . The majority of pharmacists were female $(n=158$, $58.3 \%$ ), and estimated to be aged between 20 and 40 years of age (20-30 years: $40.2 \%, 31-40$ years: $32.5 \%$, total $\mathrm{n}=197,72.7 \%$ ).

\section{Anaphylaxis preparedness}

The mean anaphylaxis preparedness score was 2.39 $(\mathrm{SD}=1.17)$ out of a possible 5 points $(\mathrm{n}=271)$. Scores for new-look EpiPen were significantly higher than for original EpiPen and Anapen (2.75 vs 2.38 points, $\mathrm{p}=0.027$; 2.75 vs 2.03 points, $\mathrm{p}<0.001$, respectively). Most pharmacists demonstrated an understanding that antihistamines are ineffective in treating anaphylaxis $(\mathrm{n}=246,90 \%)$, while two-thirds advised the patient to call an ambulance after administering an epinephrine autoinjector $(n=163$, $60.1 \%$ ). Although the majority of pharmacists discussed the symptoms of anaphylaxis $(n=176,64.9 \%)$, significantly fewer were from the Anapen group $(n=37$, $\mathrm{p}<0.001)$. Few pharmacists correctly demonstrated the epinephrine autoinjector $(\mathrm{n}=47,17.3 \%)$, or asked whether the patient had an anaphylaxis action plan

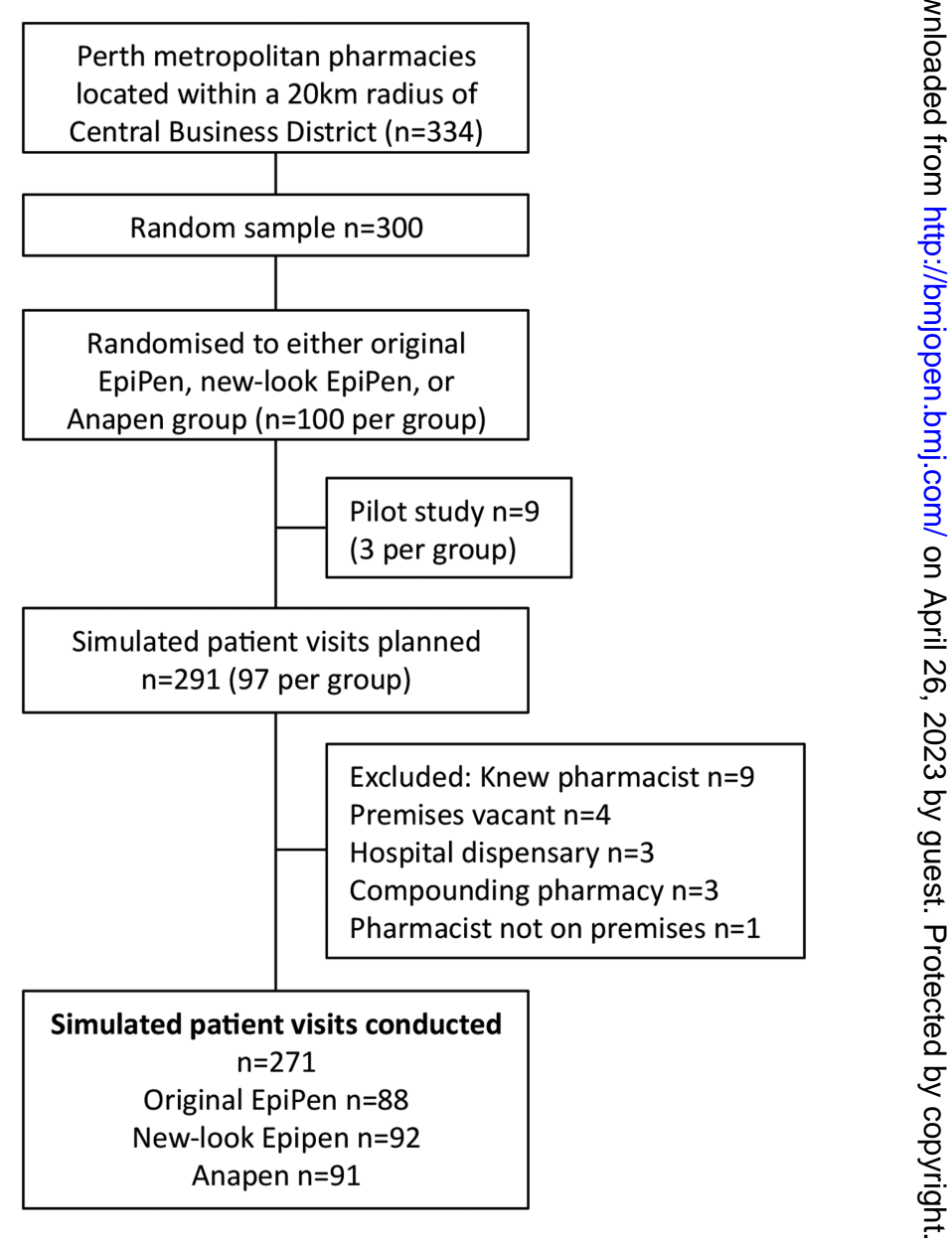

Figure 1 Participation in the PRAC study. 
Table 1 Study characteristics by epinephrine autoinjector device group (count and \%)

\begin{tabular}{|c|c|c|c|c|c|}
\hline Characteristic & $\begin{array}{l}\text { Original } \\
\text { EpiPen } \\
\mathrm{n}=88(\mathbf{3 2 . 5})\end{array}$ & $\begin{array}{l}\text { New-look } \\
\text { EpiPen } \\
\mathrm{n}=92(33.9)\end{array}$ & $\begin{array}{l}\text { Anapen } \\
\mathrm{n}=91 \\
\mathbf{( 3 3 . 6 )} \\
\end{array}$ & $\begin{array}{l}\text { Total } \\
\mathrm{n}=271 \\
(100) \\
\end{array}$ & p Value ${ }^{*}$ \\
\hline \multicolumn{6}{|l|}{ Pharmacy demographics $(n=271)$} \\
\hline Pharmacy type & & & & & 0.05 \\
\hline Independent & $44(50)$ & $47(51.1)$ & 39 (42.9) & $130(48)$ & \\
\hline Chain & 31 (35.2) & $40(43.5)$ & $47(51.6)$ & $118(43.5)$ & \\
\hline Discount/warehouse & $13(14.8)$ & $5(5.4)$ & $5(5.5)$ & $23(8.5)$ & \\
\hline Pharmacy location & & & & & $0.004 \dagger$ \\
\hline Street & $52(59.1)$ & 49 (53.3) & $30(33)$ & $131(48.3)$ & \\
\hline Medical centre & $8(9.1)$ & $6(6.5)$ & $13(14.3)$ & $27(10)$ & \\
\hline Shopping centre & $27(30.7)$ & $37(40.2)$ & $44(48.4)$ & $108(39.9)$ & \\
\hline Private hospital outpatient facility & $1(1.1)$ & $0(0)$ & $4(4.4)$ & $5(1.8)$ & \\
\hline \multicolumn{6}{|l|}{ Pharmacist demographics $(n=271)$} \\
\hline Gender & & & & & 0.90 \\
\hline Male & $35(39.8)$ & 39 (42.4) & 39 (42.9) & $113(41.7)$ & \\
\hline Estimated age (years) & & & & & $0.03 \dagger$ \\
\hline $20-30$ & 36 (40.9) & $46(50)$ & $27(29.7)$ & $109(40.2)$ & \\
\hline $31-40$ & $32(36.4)$ & $20(21.7)$ & 36 (39.6) & $88(32.5)$ & \\
\hline $41-50$ & $11(12.5)$ & $18(19.6)$ & $22(24.2)$ & $51(18.8)$ & \\
\hline $51-60$ & $9(10.2)$ & 7 (7.6) & $5(5.5)$ & $21(7.7)$ & \\
\hline $60+$ & $0(0)$ & $1(0.4)$ & $1(0.4)$ & $2(0.7)$ & \\
\hline \multicolumn{6}{|l|}{ Anaphylaxis preparedness $(n=271)$} \\
\hline Discuss any of the symptoms of anaphylaxis & 65 (73.9) & $74(80.4)$ & 37 (40.7) & $176(64.9)$ & $<0.001$ \\
\hline Call ambulance after using epinephrine autoinjector & $54(61.4)$ & $60(65.2)$ & $49(53.8)$ & $163(60.1)$ & 0.28 \\
\hline Ask about an action plan for anaphylaxis & $4(4.5)$ & $10(10.9)$ & $1(1.1)$ & $15(5.5)$ & 0.01 \\
\hline Correctly demonstrate epinephrine autoinjector & $8(9.1)$ & $22(23.9)$ & $17(18.7)$ & 47 (17.3) & 0.03 \\
\hline $\begin{array}{l}\text { Antihistamines are ineffective in treating acute } \\
\text { anaphylaxis }\end{array}$ & $78(88.6)$ & 87 (94.6) & $81(89)$ & $246(90.8)$ & 0.30 \\
\hline \multicolumn{6}{|l|}{ Anaphylaxis engagement $(n=271)$} \\
\hline Ask about the allergen that caused anaphylaxis & 67 (76.1) & $67(72.8)$ & $47(51.6)$ & $181(66.8)$ & 0.001 \\
\hline Confirm seeing an allergy specialist & $6(6.8)$ & $16(17.4)$ & $32(35.2)$ & 54 (19.9) & $<0.001$ \\
\hline Physically demonstrate the epinephrine autoinjector & 70 (79.5) & 72 (78.3) & $77(84.6)$ & $219(80.8)$ & 0.52 \\
\hline $\begin{array}{l}\text { Provide written material on how to use the } \\
\text { epinephrine autoinjector }\end{array}$ & $25(28.4)$ & $21(22.8)$ & $25(27.5)$ & $71(26.2)$ & 0.66 \\
\hline Provide advice about autoinjector storage & $20(22.7)$ & $16(17.4)$ & $16(17.6)$ & $52(19.2)$ & 0.52 \\
\hline Check epinephrine autoinjector expiry date & $54(61.4)$ & 38 (41.3) & $42(46.2)$ & $134(49.4)$ & 0.02 \\
\hline Explain side effects of epinephrine & $7(8)$ & $9(9.8)$ & $5(5.5)$ & $21(7.7)$ & 0.55 \\
\hline General anaphylaxis advice provided without prompt & 43 (48.9) & $47(51.1)$ & $20(22)$ & $110(40.6)$ & $<0.001$ \\
\hline \multicolumn{6}{|c|}{ Antihistamine $(\mathrm{AH})$ advice with sale $(n=114)$} \\
\hline AH was recommended and sold & $43(48.9)$ & $48(52.2)$ & $23(25.2)$ & $114(42.1)$ & $<0.001$ \\
\hline Choice of sedating or non-sedating $\mathrm{AH}$ offered & $5(11.6)$ & 15 (31.3) & $1(23.7)$ & $21(18.4)$ & 0.01 \\
\hline $\mathrm{AH}$ dose stated & $29(67.4)$ & $40(83.3)$ & $9(39.1)$ & 78 (68.4) & 0.001 \\
\hline $\begin{array}{l}\text { If no improvement after } \mathrm{AH} \text {, use epinephrine } \\
\text { autoinjector }\end{array}$ & $24(55.8)$ & $33(68.8)$ & $8(34.8)$ & $65(57)$ & 0.03 \\
\hline
\end{tabular}

$(\mathrm{n}=15,5.5 \%)$. Demonstrations were significantly poorer in the original EpiPen group ( $\mathrm{n}=8$ correct; $\mathrm{p}=0.03$ ), while only one pharmacist in the Anapen group asked about an action plan ( $\mathrm{p}=0.01$ compared to other groups; figure 2 , table 1$)$.

\section{Anaphylaxis engagement}

The mean anaphylaxis engagement score was 3.11 $(\mathrm{SD}=1.73)$ out of a possible 8 points $(\mathrm{n}=271)$. Scores for new-look EpiPen were similar to original EpiPen and
Anapen (3.11 vs 3.32 points; 3.11 vs 2.90 points, both $\mathrm{p}=0.42$ ), although there were differences in the points addressed by pharmacists. While most performed a hands-on demonstration with the epinephrine autoinjector or a trainer device $(n=219,80.8 \%)$, less were willing to provide written material $(\mathrm{n}=71,26.2 \%)$. Two-thirds asked about the allergen that caused anaphylaxis $(n=181,66.8 \%)$, however only $54(19.9 \%)$ of pharmacists asked whether the patient was seeing an allergy specialist (significantly more of them from the Anapen group; 
$\mathrm{n}=32, \mathrm{p}<0.001$ ). Half of the pharmacists checked the expiry date of the autoinjector $(n=134,49.4 \%)$, with significantly more checking the original EpiPen expiry $(\mathrm{n}=54, \mathrm{p}=0.02)$. Few pharmacists explained the side effects of epinephrine $(\mathrm{n}=21,7.7 \%)$ or provided advice about autoinjector storage $(n=52,19.2 \%)$. Less than half of the pharmacists provided anaphylaxis advice before the antihistamine 'prompt' question was asked by the patient $(n=110,40.6 \%)$, with significantly fewer of them in the Anapen group $(n=20, p<0.001$; figure 2, table 1$)$.

\section{Factors impacting on anaphylaxis preparedness}

Two factors associated with anaphylaxis preparedness were identified in the multiple regression model: anaphylaxis engagement score and type of epinephrine autoinjector. For each additional engagement point identified by the pharmacist, anaphylaxis preparedness increased by $7 \%$ ( 0.357 points; $95 \%$ CI 0.291 to 0.424 ; $\mathrm{p}<0.001$ ). Relative to original EpiPen (set as reference level), the new-look EpiPen was associated with an $11 \%$ increase (0.548 points; $95 \%$ CI 0.307 to $0.789 ; \mathrm{p}<0.001)$ in anaphylaxis preparedness. There was a non-significant decrease of $4.5 \%$ with Anapen $(-0.225$ points; $95 \%$ CI -0.509 to $0.059 ; \mathrm{p}=0.12$ ). Pharmacy type and location, pharmacist gender, estimated age and busyness and the time of day the visit was performed did not significantly impact on anaphylaxis preparedness, and were excluded from the final model. The fitted model equation was: anaphylaxis preparedness score $=1.091+0.548$ (new-look EpiPen) $+0.357 \times$ engagement score; adjusted $\mathrm{R}^{2}=0.327$.

\section{Antihistamine recommendations}

There were 114 pharmacists who sold an antihistamine to the patient. Sales were similar for original EpiPen and new-look EpiPen (around 50\% of visits included a sale), but significantly fewer for Anapen (25\% of visits, $\mathrm{p}<0.001$ ). There was some diversity in antihistamines recommended and sold. Where sales were made, $45(39.5 \%)$ were for first-generation $\mathrm{H}_{1}$ antagonists and $69(60.5 \%)$ were for second-generation $\mathrm{H}_{1}$ antagonists; $\mathrm{p}=0.139$. The most frequently sold antihistamine was fexofenadine $(42.1 \%)$, followed by dexchlorpheniramine $(21.1 \%)$, promethazine $(18.4 \%)$, loratidine $(12.3 \%)$, cetirizine $(4.4 \%)$, levocetirizine and desloratidine (both $0.9 \%$ ); $\mathrm{p}=0.05$.

\section{DISCUSSION \\ Principal findings}

The Pharmacists' Response to Anaphylaxis in the Community (PRAC) study was the first to measure community pharmacists' management of anaphylaxis. We found pharmacists were not fully prepared for anaphylaxis emergencies. Overall, they provided sound advice on anaphylaxis symptoms, the need for emergency care after epinephrine and the role of antihistamines. However, most pharmacists did not correctly demonstrate the epinephrine autoinjector and very few identified the need for an anaphylaxis action plan. Pharmacists appeared to be more at ease with the new-look Epipen than any other device, consistently scoring higher on all anaphylaxis preparedness measures (and thus overall score) when demonstrating this device. Despite being directly sought by the

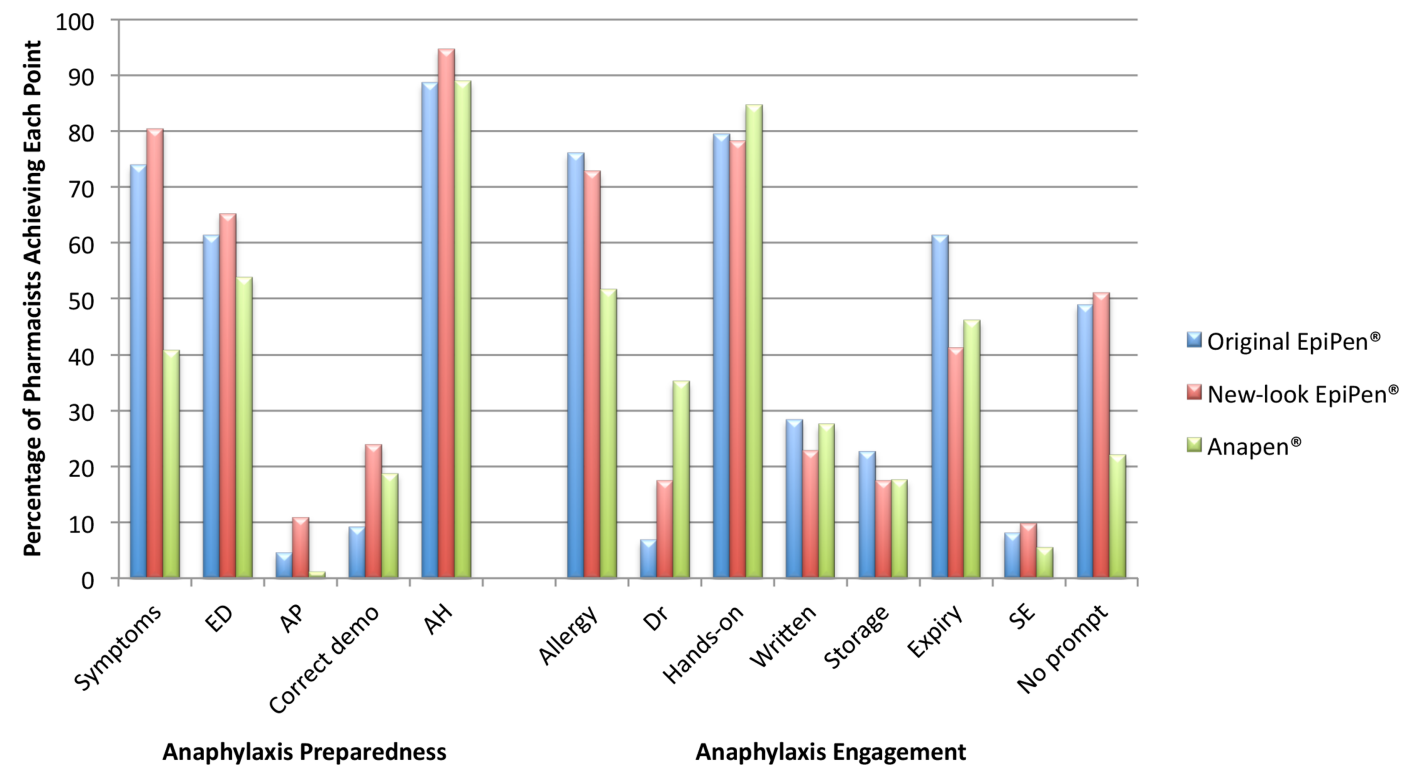

Figure 2 Anaphylaxis preparedness and engagement. Symptoms=discussed any of the symptoms of anaphylaxis with the patient; $E D=$ call an ambulance (go to emergency department) after epinephrine; $A P=$ asked if the patient had an action plan for anaphylaxis; Correct demo=correctly performed all steps for autoinjector administration; $\mathrm{AH}=$ correct antihistamine advice provided; Allergy=asked about the allergen that caused anaphylaxis; Dr=asked if the patient was seeing an allergy specialist; Hands-on=physically demonstrated the autoinjector; Written=provided written material; Storage=advised on correct autoinjector storage; Expiry=checked expiry date of the autoinjector; SE=discussed side effects of epinephrine; No prompt=anaphylaxis advice provided before the antihistamine prompt question. 
patient, pharmacists missed the opportunity to fully engage in a discussion about anaphylaxis, with less than half initiating the discussion unprompted. On average, just three of eight elements of anaphylaxis engagement were addressed. However, engagement remains vitally important: pharmacists who engaged in a discussion about anaphylaxis with the patient, also demonstrated a greater preparedness for anaphylaxis emergencies.

\section{Strengths and limitations}

A key strength of the PRAC study was the use of simulated patient methodology. This technique is well described in the literature as a tool to measure true pharmacist practice, and overcomes the issues of participant bias that occur when pharmacists know they will be evaluated. ${ }^{35}{ }^{36}$ Simulated patient methodology has been adopted worldwide in pharmacy practice research, ${ }^{37-42}$ and is an intrinsic part of quality use of medicines assessment in Australia. ${ }^{43}$

There are other strengths in our study design. Our random sample of 300 pharmacies represented over $70 \%$ of all pharmacies in the Perth metropolitan area. We defined anaphylaxis preparedness and engagement based on national and international pharmacy practice and anaphylaxis guidelines. ${ }^{20}$ 31-33 The scenario and data collection tool were developed using a rigorous approach, with training, evaluation and pilot testing undertaken prior to the study. Finally, our study had sufficient power to detect a $10 \%$ or greater difference in mean anaphylaxis preparedness score between groups.

However, there are potential limitations with the PRAC study. As we did not seek ethics approval to conduct concealed audio or video recordings and instead relied on researchers to remember details of each encounter before completing the data collection tool, this study was subject to recall bias. Our results may understate pharmacists' true preparedness scores, as simulated patient recall has been shown to underestimate real behaviour by $10-20 \% .{ }^{44}$ Although pharmacists performed better overall using the new-look EpiPen, this effect may have been confounded by features unique to the simulated patient (eg, age, gender, personality and memory). We did not measure whether the pharmacist advised the anaphylaxis patient to lay flat. We acknowledge that an upright position is associated with fatal anaphylaxis, and not measuring this important element of advice may distort anaphylaxis preparedness. We included all points stated by the pharmacist, whether they were provided before or after the antihistamine 'prompt' question. Although this may have overstated anaphylaxis preparedness or anaphylaxis engagement, we considered this aspect of the scenario important to allow pharmacists a reasonable opportunity to demonstrate their management of patients with anaphylaxis. For pharmacists to achieve all points required an extended consultation for which the pharmacist could not expect to be remunerated, and this may have affected willingness to engage in discussion.
Furthermore, we did not include workload in our definition of busyness, and could not account for attitudes to provision of information where the pharmacist had not supplied the epinephrine autoinjector. Nonetheless, in this regard pharmacists performed admirably, providing advice for free and genuinely aiming to assist the simulated patient. Such practice mirrors the ethos of Australian professional practice standards, where the pharmacist's primary concern is the health and wellbeing of the patient. ${ }^{32}$

\section{PRAC relative to other research}

Anaphylaxis management in pharmacy practice has not previously been defined or holistically evaluated. Although aspects of pharmacist management have been assessed (using survey data), the evidence for anaphylaxis preparedness or engagement is limited by few studies. A retrospective survey of 1887 patients with food-anaphylaxis found pharmacists' advice provision to be poor. In firsttime epinephrine autoinjector supplies (similar to our recently diagnosed patient), $86.6 \%$ of pharmacists provided no advice, $13.4 \%$ provided information about epinephrine (7.7\% in PRAC), $2.3 \%$ discussed the signs of an allergic reaction $(64.9 \%$ in PRAC) and $13.3 \%$ provided autoinjector training $\left(80.8 \%\right.$ in PRAC).$^{23}$

Device demonstration accuracy in PRAC was just $17.3 \%$, but this was better than or similar to demonstration accuracy in other studies $\left(15.8 \%\right.$ of school teachers, ${ }^{45} 2 \%$ of hospital doctors, ${ }^{46} 2 \%$ of general practitioners ${ }^{47}$ and $25 \%$ of physicians were accurate. ${ }^{25}$ ) In a small survey of pharmacists' proposed actions, $55.6 \%$ of pharmacists were unsure or unwilling to administer an EpiPen in a hypothetical anaphylaxis emergency. ${ }^{27}$ The main deterrent was concern about liability, and this adds an important dimension to anaphylaxis preparedness that could not be evaluated in our study. The broader literature indicates elements of anaphylaxis advice (identification and management of anaphylaxis; willingness to provide advice), and autoinjector technique (ability and intention to demonstrate) are suboptimal among health professionals and patients. $^{6} 923$ 48-53 Although some of the results for PRAC are similar, this evidence predominately relates to isolated assessments and unlike the PRAC study, does not represent overall anaphylaxis management at a given point in time.

In other simulated patient research pharmacist advice is frequently reported as suboptimal. Pharmacists may fail to conduct a complete patient assessment before product sale, or undertake comprehensive medicines discussion with the patient. ${ }^{37-42} 5455$ In a study of advice for back pain, pharmacists addressed a median of $5 / 13$ elements of advice, similar to our (mean) 3/8 for engagement. ${ }^{38}$ In other research, the pharmacist provided correct advice with a sale of drug for insomnia but there was room for improvement in general insomnia advice. $^{39}$ This was similar to PRAC where all antihistamine sales were appropriate and included sound advice, but anaphylaxis engagement was inadequate. Seemingly, pharmacists provide the information they perceive as 
essential, yet overlook the importance of a complete discussion. ${ }^{37-39} 425455$

\section{Implications and recommendations}

Historically the role of the pharmacist in anaphylaxis management was to supply epinephrine autoinjectors on prescription. However, for a raft of reasons this role is beginning to change. Anaphylaxis is now the new epidemic in public health, and in any single year, 1 in 12 patients who have suffered anaphylaxis will experience recurrence. ${ }^{1156}$ Compliance with carrying and using epinephrine autoinjectors is poor. ${ }^{9} 112228$ 57-60 While expert opinion recommends patients self-treat with epinephrine and then attend hospital, ${ }^{10} 1920$ in practice this may be difficult. Furthermore the first episode of anaphylaxis can be fatal, ${ }^{28}{ }^{61}$ and pharmacists may be the closest health professional available in the crucial early stages, where treatment may save a life. Finally, it is impossible to control or predict the actions of a desperate person during a frightening, life-threatening emergency, and some will choose to attend a pharmacy. The recent death of a girl with acute anaphylaxis, who was refused treatment by a pharmacist in Ireland, highlights the importance of pharmacist preparedness. ${ }^{62}$

The PRAC study demonstrates pharmacists are conversant with the symptoms of anaphylaxis, the need for emergency care after epinephrine and the role of antihistamines in anaphylaxis. However, the majority of pharmacists could not correctly demonstrate an autoinjector under everyday conditions, and therefore we should question their preparedness for emergency situations. Further the apparent lack of awareness of anaphylaxis action plans raises concern. Although the benefit of such plans in anaphylaxis has not formally been established, ${ }^{63}{ }^{64}$ they are widely recommended and likely provide reassurance alongside the treatment algorithm they represent.

Pharmacists worldwide have the opportunity to practise their anaphylaxis preparedness every time they supply an autoinjector. New-look EpiPen was associated with significantly greater preparedness than other devices. In the absence of a clear difference in the proportion of correct device demonstrations compared to Anapen it is not possible to explain this irregularity and we caution against translating this finding to different levels of preparedness depending on the autoinjector. Although simply engaging the patient in a general discussion about anaphylaxis improves recall of life-saving preparedness points, pharmacists do not reliably do this. There has been a call for epinephrine autoinjectors to be made available in all public places where anaphylaxis might occur, ${ }^{19}$ and pharmacies represent a logical choice for such a location. However, incomplete anaphylaxis preparedness limits the potential for this option. The 'Orange Cross' scheme promoted through Community Pharmacy Scotland identifies pharmacies that stock high-dose and low-dose autoinjectors, where pharmacists are trained and prepared to provide emergency care in acute anaphylaxis. ${ }^{65}{ }^{66}$ Such a scheme offers a safe option for patients with anaphylaxis and may provide the infrastructure to support anaphylaxis practice guidelines for pharmacists.

\section{Future research}

Less than $20 \%$ of pharmacists correctly demonstrated all autoinjector administration steps on the relevant ASCIA Action Plan for Anaphylaxis. ${ }^{31}$ There is an urgent need to investigate the intricacies of autoinjector demonstration by pharmacists to identify the nature and significance of errors made in demonstration, and the relevance of this to anaphylaxis preparedness.

To improve anaphylaxis preparedness, we should improve anaphylaxis engagement. Research to develop and implement anaphylaxis practice guidelines for pharmacists is an important step in providing guidance for pharmacists on discussion as well as treatment of anaphylaxis.

To further safeguard patients with anaphylaxis in the Australian community, development and pilot of a programme similar to the 'Orange Cross' scheme would be useful. A well-designed programme may also alleviate pharmacist concerns about liability and costs associated with provision of epinephrine as first aid for patients with anaphylaxis presenting to the pharmacy.

\section{CONCLUSIONS}

Anaphylaxis in the community presents challenges in management. Pharmacists are a potential destination for patients with acute anaphylaxis. This covert assessment of pharmacist advice identified strengths and weaknesses in anaphylaxis preparedness. Pharmacists demonstrated reasonable knowledge of anaphylaxis symptoms and emergency care, but had poor epinephrine autoinjector technique and rarely discussed anaphylaxis action plans. Pharmacists who engaged their patients in a more comprehensive discussion about anaphylaxis were more prepared for anaphylaxis emergencies. Future research should evaluate the nature and significance of errors in pharmacists' autoinjector technique. Development of anaphylaxis practice guidelines for pharmacists may improve consistency of advice and overall preparedness.

Acknowledgements The authors would like to acknowledge Link Healthcare for providing the Anapen autoinjectors, and Alphapharm for providing the EpiPen autoinjectors used in the study. The authors would like to thank Rhoda Stewart for her assistance with data collection.

Contributors SMS designed the study, conceived the scenario and data collection tool, conducted tool validation, analysed the data, interpreted results and drafted the manuscript. BD and SdK assisted with tool design and validation and collected the data. FMS assisted with interpretation of results. RMC assisted with study design, tool development and interpretation of results. All authors contributed to and approved the final version of the paper.

Funding This work was supported by a JM O'Hara Research Grant, provided by the Pharmaceutical Society of Western Australia.

Competing interests SMS is the recipient of a University Postgraduate Award and UWA Top-Up Scholarship, provided by The University of Western Australia. 
Ethics approval The University of Western Australia Human Research Ethics Committee.

Provenance and peer review Not commissioned; externally peer reviewed.

Data sharing statement No additional data are available.

Open Access This is an Open Access article distributed in accordance with the Creative Commons Attribution Non Commercial (CC BY-NC 4.0) license which permits others to distribute, remix, adapt, build upon this work noncommercially, and license their derivative works on different terms, provided the original work is properly cited and the use is non-commercial. See: http:// creativecommons.org/licenses/by-nc/4.0/

\section{REFERENCES}

1. Sampson HA, Munoz-Furlong A, Campbell RL, et al. Second symposium on the definition and management of anaphylaxis: summary report-Second National Institute of Allergy and Infectious Disease/Food Allergy and Anaphylaxis Network symposium. $J$ Allergy Clin Immunol 2006;117:391-7.

2. Clark S, Camargo CA Jr. Epidemiology of anaphylaxis. Immunol Allergy Clin North Am 2007;27:145-63

3. Lieberman P. Epidemiology of anaphylaxis. Curr Opin Allergy Clin Immunol 2008;8:316-20.

4. Lieberman P, Camargo CA, Bohlke K, et al. Epidemiology of anaphylaxis: findings of the American College of Allergy, Asthma and Immunology Epidemiology of Anaphylaxis Working Group. Ann Allergy Asthma Immunol 2006;97:596-602.

5. Abdurrahman ZB, Kastner M, Wurman $\mathrm{C}$, et al. Experiencing a first food allergic reaction: a survey of parent and caregiver perspectives. Allergy Asthma Clin Immunol 2013;9:18.

6. Kastner M, Harada L, Waserman S. Gaps in anaphylaxis management at the level of physicians, patients, and the community: a systematic review of the literature. Allergy 2010;65:435-44.

7. Koplin JJ, Martin PE, Allen KJ. An update on epidemiology of anaphylaxis in children and adults. Curr Opin Allergy Clin Immunol 2011;11:492-6.

8. Liew WK, Williamson E, Tang ML. Anaphylaxis fatalities and admissions in Australia. J Allergy Clin Immunol 2009;123:434-42.

9. Simons F, Clark S, Camargo Jr CA, et al. Anaphylaxis in the community: learning from the survivors. J Allergy Clin Immunol 2009;124:301-6.

10. Simons FE, Ardusso LR, Dimov V, et al. World Allergy Organization Anaphylaxis Guidelines: 2013 update of the evidence base. Int Arch Allergy Immunol 2013;162:193-204.

11. Mullins R. Anaphylaxis: risk factors for recurrence. Clin Exp Allergy 2003;33:1033-40

12. Mullins RJ. Paediatric food allergy trends in a community-based specialist allergy practice, 1995-2006. Med J Aust 2007;186:618-21.

13. Poulos LM, Waters AM, Correll PK, et al. Trends in hospitalizations for anaphylaxis, angioedema, and urticaria in Australia, 1993-1994 to 2004-2005. J Allergy Clin Immunol 2007;120:878-84.

14. Lin RY, Anderson AS, Shah SN, et al. Increasing anaphylaxis hospitalizations in the first 2 decades of life: New York State, 1990-2006. Ann Allergy Asthma Immunol 2008;101:387-93.

15. Gupta R, Sheikh A, Strachan DP, et al. Burden of allergic disease in the UK: secondary analyses of national databases. Clin Exp Allergy 2004;34:520-6.

16. Osborne NJ, Koplin JJ, Martin PE et al. Prevalence of challenge-proven IgE-mediated food allergy using population-based sampling and predetermined challenge criteria in infants. $J$ Allergy Clin Immunol 2011;127:668-76 e1-2.

17. Prescott SL, Pawankar R, Allen KJ, et al. A global survey of changing patterns of food allergy burden in children. World Allergy Organ J 2013;6:21.

18. Lieberman P, Nicklas RA, Oppenheimer J, et al. The diagnosis and management of anaphylaxis practice parameter: 2010 update. J Allergy Clin Immunol 2010;126:477-80 e1-42.

19. Simons F. Anaphylaxis, killer allergy: long-term management in the community. J Allergy Clin Immunol 2006;117:367-77.

20. Simons F, Ardusso LRF, Bilú MB, et al. World Allergy Organization guidelines for the assessment and management of anaphylaxis. World Allergy Organ J 2011;4:13.

21. Simons FE. Anaphylaxis. J Allergy Clin Immunol 2010;125(2 Suppl 2):S161-81.

22. Tang MLK, Kang LW. Prevention and treatment of anaphylaxis Paediatr Child Health 2008;18:309-16.

23. Barnett CW. Need for community pharmacist-provided food-allergy education and autoinjectable epinephrine training. J Am Pharmacists Assoc 2005;45:479-85.
24. Diamond S, Salter J, Hummel D. The role of pharmacists in anaphylaxis education*. J Allergy Clin Immunol 2003;111:S102.

25. Grouhi M, Alshehri M, Hummel D, et al. Anaphylaxis and epinephrine auto-injector training: who will teach the teachers? J Allergy Clin Immuno 1999;104:190-3.

26. McMillan SS, Hattingh HL, King MA. Community pharmacists opinions of their role in administering non-prescription medicines in an emergency. Int J Clin Pharm 2011;33:800-5

27. McMillan SS, Hattingh HL, King MA. An assessment of community pharmacists' responses to hypothetical medical emergency situations. Int J Pharm Pract 2012;20:413-16.

28. Pumphrey R. Anaphylaxis: can we tell who is at risk of a fatal reaction? Curr Opin Allergy Clin Immunol 2004;4:285-90.

29. Pharmaceutical Services Branch (AU). Supplying schedule 3 medicines [Internet]. Perth, WA, Australia: Health Department, Government of Western Australia (AU), 2013 [updated June, 2013; cited 2013 Oct 30]; http://www.health.wa.gov.au/anaphylaxis/HP/

30. Urbaniak GC, Plous S. Research randomizer (version 4.0) [Internet]. Social Psychology Network, 2012 [cited 2012 Mar 2]. http://www. randomizer.org

31. Allergy. ASoCla. ASCIA action plans for anaphylaxis. Balgowlah, NSW, Australia: The Australasian Society of Clinical Immunology and Allergy; [cited 2011 August 3]. http://www.allergy.org.au/content/ view/10/3/

32. Pharmaceutical Society of Australia (AU). Professional practice standards version 4. Deakin West, ACT, Australia: PSA; [updated June 2010; cited 2012 Mar 4]. https://http://www.psa.org.au/ supporting-practice/professional-practice-standards/version-4

33. Pharmaceutical Society of Australia (AU). National competency standards. Deakin, ACT, Australia: PSA; [updated Nov 2010; cited 2012 Mar 4]. https://http://www.psa.org.au/supporting-practice/ national-competency-standards

34. Department of Biostatistics (US). PS: power and sample size calculation [Internet]. Nashville, TN: Vanderbilt University School of Medicine, 2009 [updated September 2013; cited 2013 Sep 20]; http://biostat.mc.vanderbilt.edu/wiki/Main/PowerSampleSize

35. Watson MC, Skelton JR, Bond CM, et al. Simulated patients in the community pharmacy setting-using simulated patients to measure practice in the community pharmacy setting. Pharm World Sci 2004;26:32-7.

36. Watson MC, Norris P, Granas AG. A systematic review of the use of simulated patients and pharmacy practice research. Int $J$ Pharm Pract 2006;14:83-93.

37. Berger K, Eickhoff C, Schulz M. Counselling quality in community pharmacies: implementation of the pseudo customer methodology in Germany. J Clin Pharm Ther 2005;30:45-57.

38. Chua SS, Ramachandran CD, Paraidathathu TT. Response of community pharmacists to the presentation of back pain: a simulated patient study. Int J Pharm Pract 2006;14:171-8.

39. Kippist $\mathrm{C}$, Wong $\mathrm{K}$, Bartlett $\mathrm{D}$, et al. How do pharmacists respond to complaints of acute insomnia? A simulated patient study. Int J Clin Pharm 2011;33:237-45.

40. Schneider CR, Everett AW, Geelhoed E, et al. Measuring the assessment and counseling provided with the supply of nonprescription asthma reliever medication: a simulated patient study. Ann Pharmacother 2009;43:1512-18.

41. Schneider CR, Everett AW, Geelhoed E, et al. Provision of primary care to patients with chronic cough in the community pharmacy setting. Ann Pharmacother 2011;45:402-8.

42. Tully MP, Beckman-Gyllenstrand A, Bernsten CB. Factors predicting poor counselling about prescription medicines in Swedish community pharmacies. Patient Educ Couns 2011;83:3-6.

43. Benrimoj SI, Werner JB, Raffaele C, et al. A system for monitoring quality standards in the provision of non-prescription medicines from Australian community pharmacies. Pharm World Sci 2008;30:147-53.

44. Werner JB, Benrimoj SI. Audio taping simulated patient encounters in community pharmacy to enhance the reliability of assessments. Am J Pharm Educ 2008;72:136.

45. Luu NUN, Cicutto L, Soller L, et al. Management of anaphylaxis in schools: evaluation of an epinephrine auto-injector (EpiPen) use by school personnel and comparison of two approaches of soliciting participation. Allergy Asthma Clin Immunol 2012;8:4.

46. Mehr S, Robinson M, Tang M. Doctor-How do I use my EpiPen? Pediatr Allergy Immunol 2007;18:448-52.

47. Hayman GR, Bansal JA, Bansal AS. Knowledge about using auto-injectable adrenaline: review of patients' case notes and interviews with general practitioners. BMJ 2003;327:1328

48. Arkwright PD, Farragher AJ. Factors determining the ability of parents to effectively administer intramuscular adrenaline to food allergic children. Pediatr Allergy Immunol 2006;17:227-9. 
49. Ben-Shoshan M, Clarke AE. Anaphylaxis: past, present and future. Allergy 2011;66:1-14.

50. Kapoor S, Roberts G, Bynoe Y, et al. Influence of a multidisciplinary paediatric allergy clinic on parental knowledge and rate of subsequent allergic reactions. Allergy 2004;59:185-91.

51. Patel BM, Bansal PJ, Tobin MC. Management of anaphylaxis in child care centers: evaluation 6 and 12 months after an intervention program. Ann Allergy Asthma Immunol 2006;97:813-15.

52. Sicherer $\mathrm{SH}$, Noone SA, Forman JA. Use assessment of self-administered epinephrine among food-allergic children and pediatricians. Pediatrics 2000;105:359.

53. Simons FE, Edwards ES, Read EJ Jr, et al. Voluntarily reported unintentional injections from epinephrine auto-injectors. J Allergy Clin Immunol 2010;125:419-23 e4.

54. Alte D, Weitschies W, Ritter CA. Evaluation of consultation in community pharmacies with mystery shoppers. Ann Pharmacother 2007:41:1023-30.

55. Puspitasari HP, Aslani P, Krass I. A review of counseling practices on prescription medicines in community pharmacies. Res Social Adm Pharm 2009;5:197-210.

56. Simons FE, Sampson HA. Anaphylaxis epidemic: fact or fiction? J Allergy Clin Immunol 2008;122:1166-8.

57. Blyth T, Sundrum R. Adrenaline autoinjectors and schoolchildren: a community based study. Arch Dis Childhood 2002;86:26.

58. Kane KE, Cone DC. Anaphylaxis in the prehospital setting. J Emerg Med 2004;27:371-7.
59. Kim JS, Sinacore JM, Pongracic JA. Parental use of EpiPen for children with food allergies. J Allergy Clin Immunol 2005;116:164-8.

60. Monks $\mathrm{H}$, Gowland MH, MacKenzie $\mathrm{H}$, et al. How do teenagers manage their food allergies? Clin Exp Allergy 2010;40:1533-40.

61. Pumphrey RSH, Gowland MH. Further fatal allergic reactions to food in the United Kingdom, 1999-2006. J Allergy Clin Immuno 2007;119:1018-19.

62. Raidió Teilifís Éireann (RTE). Pharmaceutical Society of Ireland investigating death of teenager after peanut reaction. [Internet]. Dublin, (Ireland). 2013 [updated Dec 20; cited 2014 Feb 12]. http:// www.rte.ie/news/2013/1220/494102-emma-sloan/

63. Choo K, Sheikh A. Action plans for the long-term management of anaphylaxis: systematic review of effectiveness. Clin Exp Allergy 2007;37:1090-4.

64. Nurmatov U, Worth A, Sheikh A. Anaphylaxis management plans for the acute and long-term management of anaphylaxis: a systematic review. J Allergy Clin Immunol 2008;122:353-61, 61 e1-3.

65. Buckland L. Pharmacies to offer allergic reaction treatment [Internet]. Edinburgh, (Scotland), 2013 [updated August 2013; cited 2014 Feb 12]. http://www.scotsman.com/news/health/ pharmacies-to-offer-allergic-reaction-treatment-1-3038842

66. Community Pharmacy Scotland (UK). Anaphylaxis campaign. [Internet]. Edinburgh, (Scorland), 2014 [cited 2014 Feb 12]. http:// www.communitypharmacyscotland.org.uk/news,-policy-andpublications/policy/anaphylaxis-campaign/anaphylaxis-campaign/ 